\title{
Chemically Modified Interleukin-6 Aptamer Inhibits Development of Collagen-Induced Arthritis in Cynomolgus Monkeys
}

\author{
Masao Hirota, Ikuo Murakami, ${ }^{1}$ Yuichi Ishikawa, ${ }^{1}$ Tomoki Suzuki, ${ }^{1}$ Shun-ichiro Sumida, \\ Shigeru Ibaragi, ${ }^{1}$ Hayato Kasai, ${ }^{2}$ Naoto Horai, ${ }^{2}$ Daniel W. Drolet, ${ }^{3}$ Shashi Gupta, ${ }^{3}$ \\ Nebojsa Janjic, ${ }^{3}$ and Daniel J. Schneider ${ }^{3}$
}

Interleukin-6 (IL-6) is a potent mediator of inflammatory and immune responses, and a validated target for therapeutic intervention of inflammatory diseases. Previous studies have shown that SL1026, a slow off-rate modified aptamer (SOMAmer) antagonist of IL-6, neutralizes IL-6 signaling in vitro. In the present study, we show that SL1026 delays the onset and reduces the severity of rheumatoid symptoms in a collagen-induced arthritis model in cynomolgus monkeys. SL1026 (1 and $10 \mathrm{mg} / \mathrm{kg})$, administered q.i.d., delayed the progression of arthritis and the concomitant increase in serum IL-6 levels compared to the untreated control group. Furthermore, SL1026 inhibited IL-6-induced STAT3 phosphorylation ex vivo in T lymphocytes from human blood and IL-6-induced C-reactive protein and serum amyloid A production in human primary hepatocytes. Importantly, SOMAmer treatment did not elicit an immune response, as evidenced by the absence of antiSOMAmer antibodies in plasma of treated monkeys. These results demonstrate that SOMAmer antagonists of IL-6 may be attractive agents for the treatment of IL-6-mediated diseases, including rheumatoid arthritis.

\section{Introduction}

$\mathbf{R}$ HEUMATOID ARTHRITIS (RA) Is an autoimmune inflammatory disease associated with persistent synovitis and progressive joint damage [1,2]. Although the causes of RA are not fully understood, proinflammatory cytokines, such as tumor necrosis factor-alpha, interleukin-1 (IL-1) and interleukin-6 (IL-6), are known to be involved in the progression of this disease [3-6]. Constitutive overproduction of IL-6 is observed in the synovial fluid, bone marrow, and serum of patients with RA [7-11]. IL-6 activity in synovial fluid is greater than in serum [8], indicating that IL-6 is generated from activated and/or inflamed cells in articular cavities and is subsequently released into serum. The abnormally high concentration of IL-6 exacerbates disease progression, and normalization of serum IL-6 levels is an effective treatment for this disease [12,13].

There is no cure for RA, and current treatments are designed to slow progression of the disease. First-line therapies for RA include nonsteroidal anti-inflammatory drugs and small-molecule disease-modifying antirheumatic agents such as methotrexate; however, there is a growing role for biological agents, including tocilizumab, a humanized anti-IL-6 receptor antibody [14] that blocks IL-6 signaling. Tocilizu$\mathrm{mab}$ is an approved drug for treatment of RA and other diseases mediated by IL-6, such as Castleman's disease, juvenile idiopathic arthritis, and Crohn's disease [14-16].

IL-6 is a pleiotropic cytokine that regulates immune response, inflammation, hematopoiesis, and bone metabolism [17-20]. IL-6 activates cells by binding to its specific nonsignaling IL-6 receptor $\alpha$ (IL-6R, gp80, or CD126) present on the cell membrane. This ligand-receptor complex then binds to the signal-transducing protein gp130 (CD130) and activates the JAK-STAT3 (Janus kinasesignal transducers and activators of transcription 3) signaling pathway [21,22], resulting in STAT3 phosphorylation, a critical step in many IL-6 activities [23-25]. Soluble IL-6R (sIL-6R) in blood and other body fluids binds to IL-6, but

\footnotetext{
${ }^{1}$ Otsuka Pharmaceutical Co., Ltd., Tokushima, Japan.

${ }^{2}$ Shin Nippon Biomedical Laboratories, Ltd., Drug Safety Research Laboratories, Kagoshima, Japan.

${ }^{3}$ SomaLogic, Inc., Boulder, Colorado.

(C) Masao Hirota et al, 2015; Published by Mary Ann Liebert, Inc. This Open Access article is distributed under the terms of the Creative Commons License (<http://creativecommons.org/licenses/by/4.0 >), which permits unrestricted use, distribution, and reproduction in any medium, provided the original work is properly credited.
} 
instead of acting as an antagonist, sIL-6R increases the half-life of IL-6 and activates the signaling pathway in cells which do not express the membrane-bound IL-6R $\alpha$ [26-28].

We previously reported the discovery and optimization of SL1025, a single-stranded DNA slow off-rate modified aptamer (SOMAmer) that binds with high affinity to human $\left(\mathrm{K}_{\mathrm{d}}=0.2 \mathrm{nM}\right)$ and monkey $\left(\mathrm{K}_{\mathrm{d}}=2.5 \mathrm{nM}\right)$ IL-6 and inhibits IL-6-dependent cell signaling pathways [29]. Similar to traditional aptamers, SOMAmers are selected in vitro from large random libraries, but are uniformly functionalized with hydrophobic moieties (eg, benzyl-, 2-naphthyl-, or 3-indolylcarboxamide) at the 5-position of uridine through a carboxamide linker [30]. These hydrophobic groups can participate in interactions with target molecules as well as form novel intramolecular secondary and tertiary structural motifs $[31,32]$. In addition to improved affinities, which are comparable to those of antibodies, SOMAmer technology offers several advantages over traditional aptamers, including enhanced nuclease resistance and greater selection success rates [33].

SL1025 is a 32 nucleotide sequence with ten hydrophobic modifications (eight benzyl, one naphthylmethyl and one phenylethyl), as well as six 2'-methoxy ribose modifications to further enhance nuclease stability (Fig. 1A). Analysis of the crystal structure of SL1025 in a complex with IL-6 revealed that the majority of the IL- 6 contact surfaces for both IL-6R and gp130 are occluded by SL1025 in the complex [31] (Fig. 1B, C). Furthermore, nearly all of the hydrophobic modifications are clustered on one side of SL1025 and make direct contact with IL-6.
SL1026 is a PEGylated form of SL1025 and has similar affinity $\left(\mathrm{K}_{\mathrm{d}}=0.2 \mathrm{nM}\right)$ for human IL-6 and similar inhibition activity for human IL-6 [29] and monkey IL-6 (data not shown). In this study, we report that SL1026 can delay the progression of RA in a nonhuman primate collagen-induced arthritis (CIA) model. We also show that SL1026 can inhibit STAT3 phosphorylation in human T lymphocytes as well as C-reactive protein (CRP) and serum amyloid A (SAA) protein production in human primary hepatocytes. Taken together, these results show that SL1026 is a potent antagonist of the IL-6 signaling pathway and represents a potential new drug candidate for the treatment of IL-6-mediated diseases, including RA.

\section{Materials and Methods \\ Reagents}

SL1026 was prepared with a hexylamine modification at the $5^{\prime}$ terminus by solid phase synthesis at Agilent Technologies (Boulder, CO) as described previously [29]. Polyethylene glycol (PEG) (branched $2 \times 20 \mathrm{kDa}$ NHS ester; JenKem Technology, Plano, TX) was conjugated to the terminal amine using standard methods. SOMAmer concentrations for all studies were calculated using only the mass of the DNA component (excluding the mass of the PEG component). SL1026 for animal studies was tested for bacterial endotoxin contamination by the Limulus amebocyte lysate method [34] and determined to be below the lower limit of assay detection $(<0.009 \mathrm{EU} / \mathrm{mg})$. Human recombinant IL-6 was purchased from Millipore, Inc. (Billerica, MA). Tocilizumab (Actemra ${ }^{\circledR} 200 \mathrm{mg}$ ) was manufactured by Genentech, Inc. (San Francisco, CA).

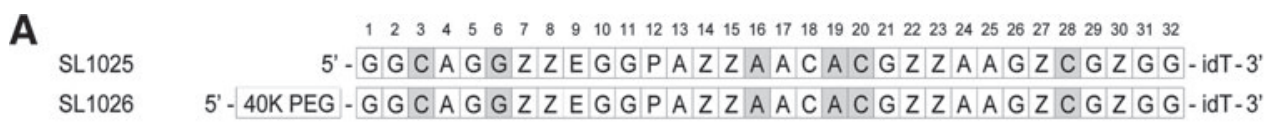

B

IL-6·SL1025

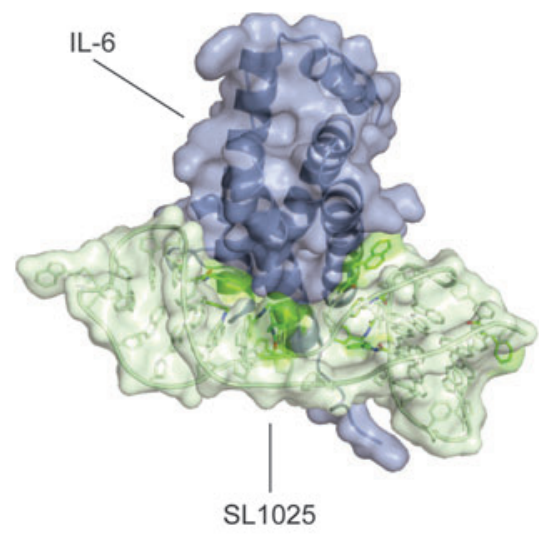

C IL-6・IL-6R・gp130

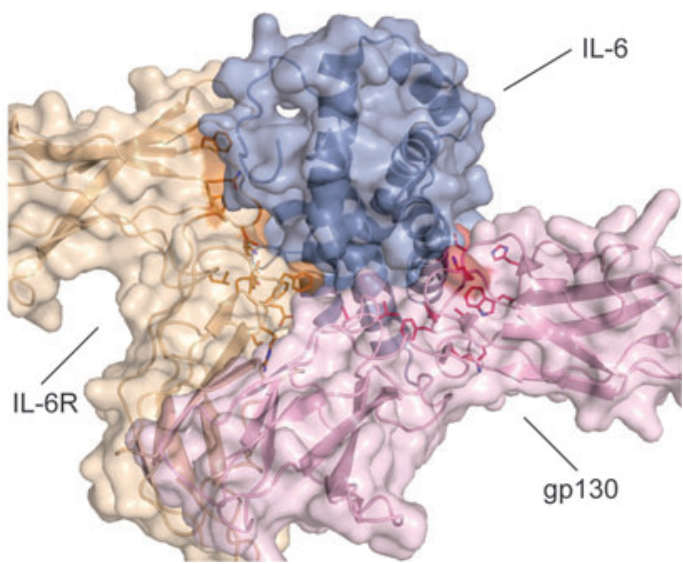

FIG. 1. SL1025 occludes binding sites of IL-6R and gp130. (A) Sequences of SL1025 and SL1026 with 5-dU modifications indicated $\left(\mathrm{Z}=\right.$ benzyl, $P=$ naphthyl, $\mathrm{E}=$ phenethyl) and $2^{\prime}$-methoxy positions highlighted gray. SL1026 is comprised of SL1025 with a $40 \mathrm{kDa}$ polyethylene glycol (PEG) conjugated to its $5^{\prime}$ terminus. Both sequences have a $3^{\prime}$ inverted dT (idT). (B) X-ray crystal structure of the IL-6:SL1025 complex in a cartoon and transparent surface rendering representation (PDB ID: 4NI9) [31]. IL-6 is colored blue, and SL1025 is colored green. Hydrophobic modifications in SL1025 that make direct contact with IL-6 are highlighted green. (C) X-ray crystal structure of the IL-6:IL-6R:gp130 complex in a cartoon and transparent surface rendering representation (PDB ID: 1P9M) [67]. IL-6 is colored blue, IL-6R is colored brown, and gp130 is colored pink. 
Measurement of STAT3 inhibition

Measurement of STAT3 phosphorylation in T lymphocytes was conducted as described previously [35]. Whole blood was collected from the antecubital vein of 10 healthy Japanese human volunteers. SL1026 or tocilizumab was preequilibrated with human recombinant IL-6 $(10 \mu \mathrm{g} / \mathrm{mL}$, $0.4 \mu \mathrm{M}$ ) and incubated with $200 \mu \mathrm{L}$ of human blood for $20 \mathrm{~min}$ at $37^{\circ} \mathrm{C}$. After removing the red blood cells with fluorescence activated cell sorting (FACS) lysing solution (BD Biosciences, San Diego, CA), the cells were suspended in $1 \mathrm{~mL}$ of methanol to permeabilize the cell membrane. Methanol was removed and the cells were then resuspended in $100 \mu \mathrm{L}$ of FACS buffer (phosphate buffered saline [PBS] containing $2 \%$ fetal bovine serum) containing 10\% AlexaFluor 488-conjugated anti-p-STAT3 antibody (BD Biosciences), $0.2 \%$ PE-conjugated anti-CD3 antibody (BD Biosciences), and $0.2 \%$ PerCP-conjugated anti-CD4 antibody (BD Biosciences). After incubation for $1 \mathrm{~h}$ on ice, the cells were resuspended in $700 \mu \mathrm{L}$ of FACS buffer. Samples were analyzed using a FACS Calibur Flow Cytometer (Becton Dickinson and Company, Tokyo, Japan), and the mean fluorescence intensity of the cells was analyzed using CellQuest software version 3.3 (Becton Dickinson and Company). Protocols were approved by the Ethics Committee of the Otsuka Pharmaceutical Company and conducted in accordance with the guidelines for human experimentation established by the Declaration of Helsinki. Each subject provided written informed consent to participate in the study.

\section{Measurement of CRP and SAA}

Human primary hepatocytes (KAC Co., Ltd., Kyoto, Japan) were seeded into 96-well plates at a concentration of $2.8 \times 10^{4}$ cells/well with incubation medium (KAC Co., LTD.). The following day, fresh medium was added containing human recombinant IL-6 $(10 \mathrm{ng} / \mathrm{mL})$ pre-equilibrated with SL1026 or tocilizumab. Twenty-four hours later, supernatants were collected and the concentration of CRP and SAA were determined by ELISA. CRP was measured with a CircuLex HighSensitivity CRP ELISA Kit (CircuLex Co., Ltd., Nagano, Japan), and SAA was measured with an Invitrogen Hu SAA ELISA Kit (Thermo Fisher Scientific, Inc., Waltham, MA).

\section{Animal care}

Twenty-four female cynomolgus monkeys (Macaca fasciularis), aged 3-5 years were obtained from Guangxi Grandforest Scientific Primate Company, Ltd. (Guangxi, China). Twelve monkeys were used for the pharmacokinetic study and 12 were used for the CIA model study. Animals were housed individually at a temperature of $26^{\circ} \mathrm{C} \pm 3^{\circ} \mathrm{C}$ and relative humidity of $55 \pm 20 \%$. Monkey chow (HF Primate 5K91 12G 5K9J; Purina Mills, LLC) was provided at $\sim 108 \mathrm{~g} /$ day and tap water was provided ad libitum from an automatic supply system (Edstrom Industries, Inc., Waterford, WI). Studies were performed by Shin Nippon Biomedical Laboratories, Ltd. (Kagoshima, Japan) in accordance with standards published by the National Research Council (Guide for the Care and Use of Laboratory Animals, NIH OACU) of the National Institutes of Health Policy on Human Care and Use of Laboratory Animals. In accordance with these standards, every effort was made to ensure that the animals were free of pain and discomfort.

\section{Pharmacokinetic study}

SL1026 was formulated in a vehicle consisting of $10 \mathrm{mM}$ phosphate buffer ( $\mathrm{pH} 7$ ) containing $5 \mathrm{mM} \mathrm{MgCl} 2,135 \mathrm{mM}$ $\mathrm{NaCl}$, and $0.05 \%$ (w/v) Polysorbate 20. SL1026 was administered by bolus injection into the cephalic vein. Twelve animals were assigned to 3 dose groups ( $n=4$ per group): 1,10 , and $30 \mathrm{mg} / \mathrm{kg}$. Blood was collected from the femoral vein in $\mathrm{K}_{2}$ EDTA vacutainers (BD Biosciences) at 0.083, 0.25, 0.5, 1 , $2,4,6,8,12,24,48$, and $72 \mathrm{~h}$ after dose administration. SL1026 concentrations in plasma were measured by the dual hybridization method [36]. Briefly, a capture probe with a $3^{\prime}$ amine was designed to hybridize with 17 bases on the $5^{\prime}$ terminus of SL1026, and a detection probe with a $5^{\prime}$ fluorescein isothiocyanate (FITC) label was designed to hybridize with 15 bases on the $3^{\prime}$ terminus of SL1026. The capture probe was immobilized in a 96-well activated plate (Sumitomo Bakelite, Tokyo, Japan) and the plate was washed and blocked. The detection probe was incubated with the plasma samples for $15 \mathrm{~min}$ at $80^{\circ} \mathrm{C}$ to allow annealing to SL1026. Plasma samples were then added to the capture probe plate and incubated for $2 \mathrm{~h}$ at $38^{\circ} \mathrm{C}$ to allow annealing to SL1026. After washing the plate, horseradish peroxidase (HRP)-conjugated anti-FITC antibody (Southern Biotechnology Associates, Inc., Birmingham, AL) was added to each well and incubated for $2 \mathrm{~h}$ at room temperature. After washing the plate, HRP substrate solution $\left(0.5 \mathrm{mg} / \mathrm{mL} 3,3^{\prime}, 5,5^{\prime}\right.$-tetramethylbenzidine [TMB], $0.33 \mathrm{mM}$ EDTA-2K, $0.2 \%$ acetic acid, 25\% diethylformamide) was added to each well and incubated for 7-15 min at room temperature. Reactions were stopped by the addition of $0.5 \mathrm{M}$ $\mathrm{H}_{2} \mathrm{SO}_{4}$ and absorbance was measured. Blank and standard samples were prepared for each plate and a calibration curve was used to determine the SL1026 concentration in each plasma sample. Pharmacokinetic parameters were determined by noncompartmental analyses using WinNonlin software (version 5.2.1; Pharsight Corp., St. Louis, MO).

\section{CIA study}

Twelve cynomolgus monkeys were assigned to 3 groups (4 animals per group): control and two SL1026-treated groups (1 and $10 \mathrm{mg} / \mathrm{kg} / \mathrm{dose}$ ). Arthritis was induced by collagen treatment as described previously [37]. Bovine type II collagen (K41S type 2 collagen, $0.4 \%$ solution) was purchased from Collagen Research Center (Tokyo, Japan), diluted to $4 \mathrm{mg} / \mathrm{mL}$ and then mixed with an equal volume of complete Freund's adjuvant (BD Biosciences). Monkeys were immunized on Study Day 0 by intradermal $2 \mathrm{~mL}$ injections into the back. Animals received a booster 3 weeks later (day 21) by the same procedure. SL1026 was formulated as described above and intravenous bolus doses $(1 \mathrm{~mL} / \mathrm{kg})$ were administered into the cephalic vein every $6 \mathrm{~h}$ for 11 days starting on the first day of immunization. The control group received vehicle alone following the same dosing schedule. Arthritis scores and general condition scores of monkeys were observed and recorded once a week for 5 weeks, at 6, 12, 20, 27, and 34 days after the first immunization. Clinical assessment was performed according to established methods, which were modified in consideration of joint function [37]. Arthritis scores were evaluated by monitoring the degree of swelling and rigidity at the metacarpophalangeal, proximal interphalangeal, and distal interphalangeal joints, and of the wrist, ankle, elbow, and knee (total 64 joints). Each joint was assessed according to the following evaluation 
criteria: Score 0, no abnormality; Score 1, swelling not visible, but can be determined by touch; Score 2, swelling slightly visible and can be confirmed by touch; Score 3, swelling clearly visible, but joint can be completely flexed; Score 4, swelling clearly visible, but joint cannot be completely flexed; Score 5, rigid joints. The arthritis score for each animal was designated as the total score of individual joints. General condition scores were evaluated by monitoring behavior and movement of the monkeys. Each monkey was assessed according to the following evaluation criteria: Score 0, No abnormality; Score 1, Difficulty in hanging from the bars of the home cage by the fingers; Score 2, Inability to hang from the bars of the home cage by the fingers (using wrist); Score 3, Movement only by using forelimbs or hindlimbs; Score 4, Crouching; Score 5, Abnormal body position. Arthritis and general condition scores were determined by investigators blind to treatment assignment.

\section{Measurement of SL1026, IL-6, and anti-SL1026 antibody in monkey plasma}

Blood was drawn from the femoral vein of each monkey. Samples were processed into plasma using $\mathrm{K}_{2}$ EDTA for the measurement of SL1026 concentration, or using heparin sodium (Ajinomoto Pharmaceutical Co. Ltd., Tokyo, Japan) for the measurement of IL-6 and anti-SL1026 antibody. SL1026 concentration in plasma was measured by the dual hybridization method as described above. IL-6 concentration in the plasma was measured using a Quantikine human IL-6 ELISA Kit (R\&D Systems, Inc., Minneapolis, MN). SL1026 did not interfere with the measurement of IL-6 with this kit (data not shown). AntiSL1026 antibody in the plasma was measured by ELISA. Briefly, an immunoplate (Sumitomo Bakelite) was coated with $50 \mathrm{pmol} /$ well of the DNA component or with $10 \mathrm{pmol} / \mathrm{well}$ of the PEG component of SL1026 according to the manufacturer's instructions. Monkey plasma (1,000-fold diluted) was added to each well and incubated for $2 \mathrm{~h}$ at room temperature with shaking (200 rpm). After washing the wells with PBS containing $0.05 \%$ Polysorbate, horseradish peroxidase-conjugated antihuman $\mathrm{IgG}+\operatorname{IgM}+\operatorname{IgA}(\mathrm{H} \& \mathrm{~L})$ (Biodesign, Saco, ME) was diluted 40,000-fold in PBS containing Polysorbate and added to the wells for $1 \mathrm{~h}$ at room temperature with shaking $(200 \mathrm{rpm})$. After washing, TMB substrate (Thermo Fisher Scientific) was added, and the colorimetric reaction was measured using an EMax plate reader (Molecular Devices, Tokyo, Japan) at $450 \mathrm{~nm}$. Normal cynomolgus monkey plasma served as a negative control, while an anti-DNA antibody (Millipore) and an anti-PEG antibody (Epitomics, Burlingame, CA) served as positive controls.

\section{Statistics}

Graphical presentations and calculations were carried out using Microsoft Excel 2003 (SP1; Microsoft Co., Redmond, WA). Statistical analyses were performed using SAS System for windows (release 9.1 and 9.3; SAS Institute, Inc., Cary, NC). For the ex vivo test using human lymphocytes, the Dunnett's test and unpaired $t$-test were conducted. For the monkey studies, the mixed effect model for repeated measures method was used for the comparison of clinical scores. Twotailed $P<0.05$ was considered significant. For the comparison of IL-6 concentrations on day 34, the Kruskal-Wallis test was performed comparing treatment groups with control, followed by a Dunn's post test corrected for multiplicity of comparison.

\section{Results}

Inhibition of IL-6-induced STAT3 phosphorylation in human $T$ lymphocytes

To evaluate the inhibitory effect of SL1026 on IL-6-induced phosphorylation of STAT3, we performed an ex vivo assay using human peripheral blood lymphocytes (Fig. 2). IL-6 treatment led to a 7.5-fold increase in STAT3 phosphorylation of $\mathrm{CD}^{+}$and $\mathrm{CD}^{+}$lymphocytes, compared to the vehicle control. Treatment of cells with $0.1,1$, or $10 \mu \mathrm{g} / \mathrm{mL}$ of SL1026 $(8.3,83$, or $833 \mathrm{nM})$ inhibited STAT3 phosphorylation $64.7 \pm 5.5 \%, 94.7 \pm 0.8 \%$, and $98.0 \pm 0.7 \%$ (mean $\pm \mathrm{SD}$ ), respectively. For comparison, $0.1,1$, or $10 \mu \mathrm{g} /$ $\mathrm{mL}$ of tocilizumab $(0.67,6.7$, or $67 \mathrm{nM})$ inhibited STAT3 phosphorylation $32.6 \pm 9.5 \%, 70.2 \pm 3.3 \%$, and $89.7 \pm 2.0 \%$, respectively.

\section{Inhibition of IL-6-induced CRP and SAA production in human primary hepatocytes}

To evaluate the inhibitory effect of SL1026 on IL-6-induced production of CRP and SAA, we performed an ex vivo assay using human primary hepatocytes (Fig. 3). CRP and SAA concentrations in supernatants from hepatocytes were 1.8 and $9.4 \mathrm{ng} / \mathrm{mL}$ (mean, $n=3$ ), respectively. Treatment of cells with IL-6 increased CRP concentration $\sim 2$-fold and SAA more than 10-fold compared to nonstimulated cells. Similar to tocilizumab, SL1026 showed dose-dependent inhibition of IL-6induced production of CRP and SAA.

\section{Pharmacokinetics of SL1026}

To establish a dose regimen for the CIA study, a plasma pharmacokinetic evaluation was performed in female cynomolgus monkeys following a single 1,10 , or $30 \mathrm{mg} / \mathrm{kg}$

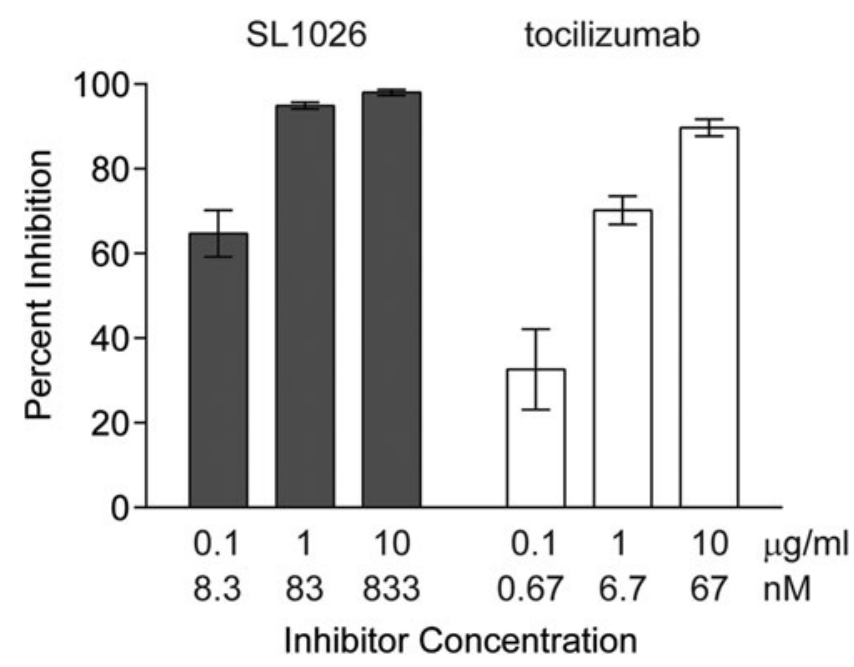

FIG. 2. SL1026 inhibits IL-6-induced STAT3 phosphorylation in human lymphocytes. Cells were induced with IL-6 and STAT3 phosphorylation was determined by FACS using a fluorescent anti-p-STAT3 antibody. Percent inhibition values (relative to no IL-6 and no inhibitor control samples) are plotted as the mean \pm SEM of 10 samples at each concentration. A statistically significant increase of inhibition was observed compared to no-inhibitor control $(0.0 \pm 2.8 \%)$ for all SL1026 and tocilizumab groups (Dunnett's test, two-tailed, $P<0.01$ ). 
A

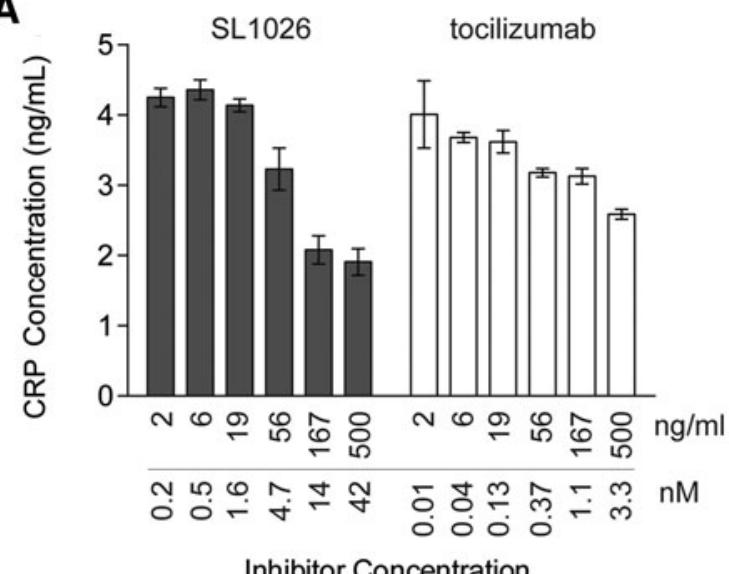

B

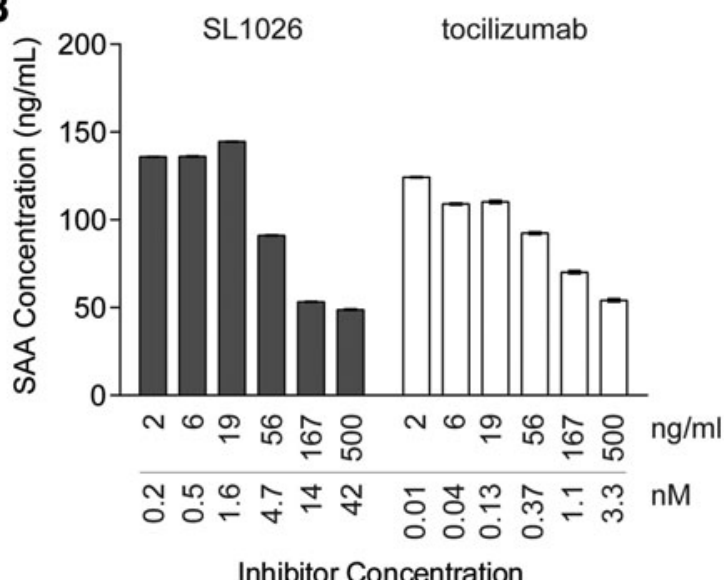

FIG. 3. SL1026 inhibits IL-6-induced C-reactive protein (CRP) and serum amyloid A (SAA) expression in human primary hepatocytes. CRP (A) and SAA (B) concentrations were measured in hepatocyte supernatants by ELISA after IL-6 treatment and plotted as a function of SL1026 or tocilizumab concentration. Values are plotted as the mean \pm SEM of three determinations.

intravenous bolus dose ( $n=4$ per group). Mean extrapolated maximum SL1026 plasma concentrations $\left(\mathrm{C}_{0}\right)$ were approximately dose linear over the 30 -fold dose range studied (Table 1). Plasma concentration-time curves showed a biphasic decline (Fig. 4) with mean terminal $\left(\mathrm{t}^{1} / 2 \beta\right)$ half-lives of $5.33,164$, and $51.8 \mathrm{~h}$ for the 1,10 , and $30 \mathrm{mg} / \mathrm{kg}$ dose groups, respectively (Table 1). As assessed by plasma area under the concentration-time curves (AUC), the increase of total SL1026 exposure with dose was greater than doseproportional, indicating saturation of plasma clearance. Thus, over the dose range studied, plasma clearance values declined 4-fold from $79.1 \mathrm{~mL} / \mathrm{h} / \mathrm{kg}$ for the low-dose group to $19.9 \mathrm{~mL} / \mathrm{h} / \mathrm{kg}$ for the high-dose group.

\section{Reduction of arthritis symptoms in monkeys treated with SL1026}

Monkeys received a q.i.d. administration of either 0,1 , or $10 \mathrm{mg} / \mathrm{kg} \mathrm{SL} 1026$ (0, 4, or $40 \mathrm{mg} / \mathrm{kg} /$ day), with the schedule of collagen treatment, plasma collection, and arthritis score assessment indicated in Fig. 5A. All monkeys in the un-
Table 1. Mean Pharmacokinetic Parameters of SL1026 After Single Bolus Administration in Cynomolgus Monkeys

\begin{tabular}{|c|c|c|c|}
\hline \multirow{2}{*}{$\begin{array}{l}\text { Pharmacokinetic } \\
\text { parameter }\end{array}$} & \multicolumn{3}{|c|}{ Dose $(\mathrm{mg} / \mathrm{kg})$} \\
\hline & 1 & 10 & 30 \\
\hline $\mathrm{C}_{0}(\mu \mathrm{g} / \mathrm{mL})$ & 25.8 & 359 & 803 \\
\hline \multicolumn{4}{|l|}{$\mathrm{t}_{1 / 2}(\mathrm{~h})$} \\
\hline$\alpha$ & 0.359 & 0.387 & 0.912 \\
\hline$\beta$ & 5.33 & 164 & 51.8 \\
\hline $\mathrm{AUC}_{\mathrm{t}}(\mathrm{h} \cdot \mu \mathrm{g} / \mathrm{mL})$ & 13.5 & 309 & 1,520 \\
\hline $\mathrm{AUC}_{\mathrm{inf}}(\mathrm{h} \cdot \mu \mathrm{g} / \mathrm{mL})$ & 13.6 & 306 & 1,520 \\
\hline CL (mL/h/kg) & 79.1 & 32.7 & 19.9 \\
\hline $\mathrm{V}_{\mathrm{z}}(\mathrm{mL} / \mathrm{kg})$ & 611 & 7,770 & 1,510 \\
\hline $\mathrm{V}_{\mathrm{ss}}(\mathrm{mL} / \mathrm{kg})$ & 39.2 & 117 & 30.9 \\
\hline
\end{tabular}

Values were calculated from three or four monkeys in each group.

$\mathrm{C}_{0}$ initial blood level; $\mathrm{t}_{1 / 2}$, half-life; $\alpha$, half-life of the first phase; $\beta$, half-life of the second phase; $\mathrm{AUC}_{\mathrm{t}}$, area under the concentrationtime curve from time 0 to the last measurable time point; $\mathrm{AUC}_{\mathrm{inf}}$, area under the plasma concentration-time curve from time 0 to infinity; $\mathrm{CL}$, clearance; $\mathrm{V}_{\mathrm{z}}$, apparent volume of distribution during the terminal phase; $\mathrm{V}_{\mathrm{ss}}$, apparent volume of distribution at steady state.

treated control group $(0 \mathrm{mg} / \mathrm{kg}$ SL1026) began to show clinical signs of arthritis on day 13, with an arthritis score of $0.3 \pm 0.3$ (mean $\pm \mathrm{SEM}$ ). This score continued to increase throughout the study and reached $93.3 \pm 22.8$ on day 34 (Fig. 5B). In contrast, no clinical signs of arthritis were detected until day 20 in monkeys treated with either 1 or $10 \mathrm{mg} / \mathrm{kg}$ SL1026. On day 34, arthritis scores for SL1026-treated animals were $68.5 \pm 10.7$ and $41.0 \pm 14.6$ for the 1 and $10 \mathrm{mg} / \mathrm{kg}$ dose groups, respectively. The reduced arthritis score of the $10 \mathrm{mg} / \mathrm{kg}$ dose group on day 34 was significantly different than the control group $(P<0.05)$. The general condition score for the untreated control monkeys also continued to worsen throughout the study, reaching a value of $3.3 \pm 0.5$ (mean \pm SEM) on day 34 (Fig. 5C), compared to $1.5 \pm 0.5$ and $1.5 \pm 0.6$ for the 1 and $10 \mathrm{mg} / \mathrm{kg}$ SL1026 treatment groups, respectively. The improved general condition score for both treatment groups on day 34 was significantly different than the control groups $(P<0.05)$. Overall,

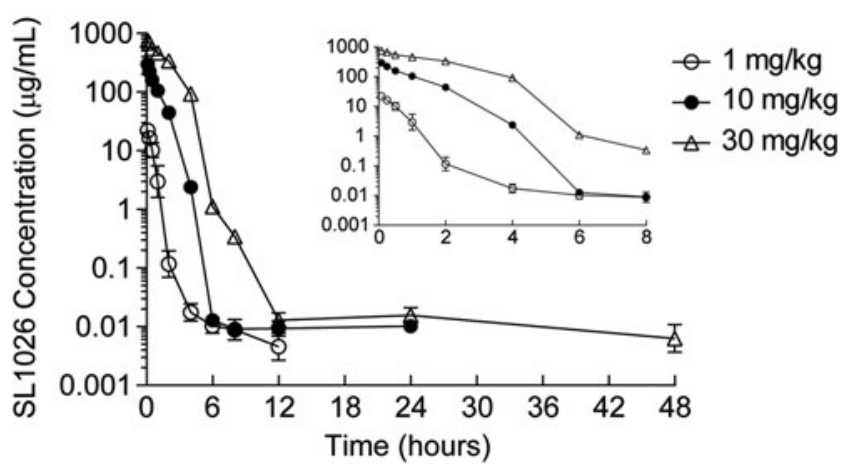

FIG. 4. Plasma concentration-time profiles of SL1026 in monkeys. Plasma SL1026 concentrations after administrations of $1(\bigcirc), 10(\bigcirc)$, or $30 \mathrm{mg} / \mathrm{kg}(\triangle)$ were measured. Values are plotted as the mean \pm SD of four monkeys. Values measured during the first $8 \mathrm{~h}$ after administration are shown in the inset plot. 
A

\begin{tabular}{|c|c|c|c|c|c|c|}
\hline & & & & & & \\
\hline Day & 0 & 7 & 14 & 21 & 28 & 35 \\
\hline Collagen Treatment & & & & r & & \\
\hline Plasma Collection & $\ldots$ &.. & . . & .. & $\theta^{\circ}$ & . \\
\hline Arthritis Score & $\cdot$ & . & . & - & . & - \\
\hline
\end{tabular}

B
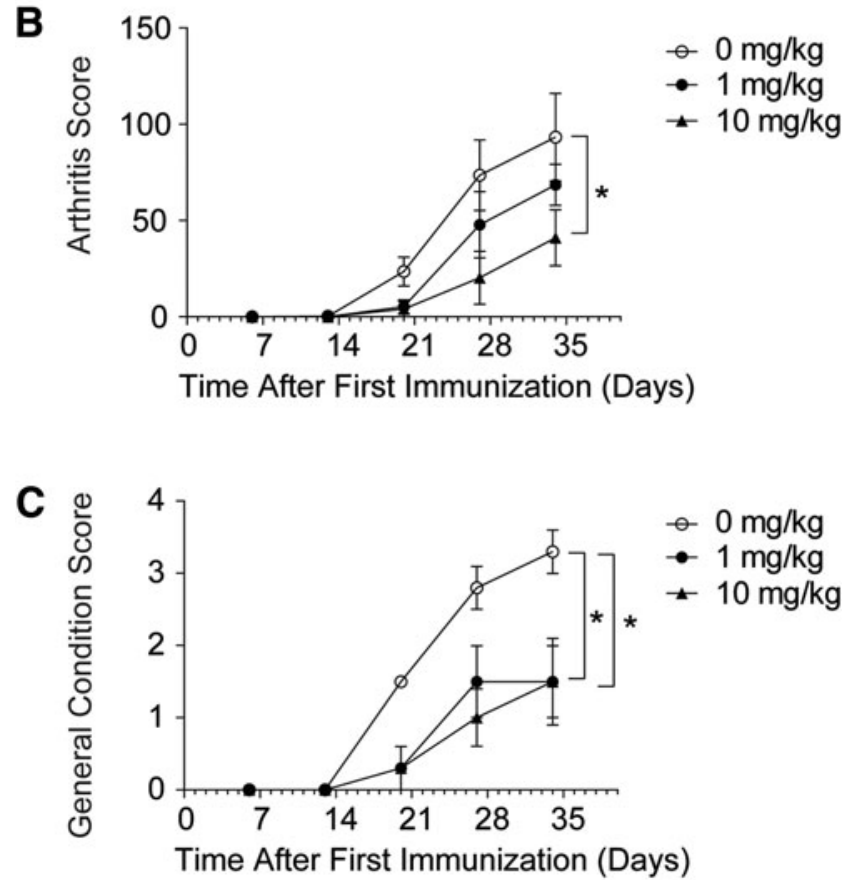

D

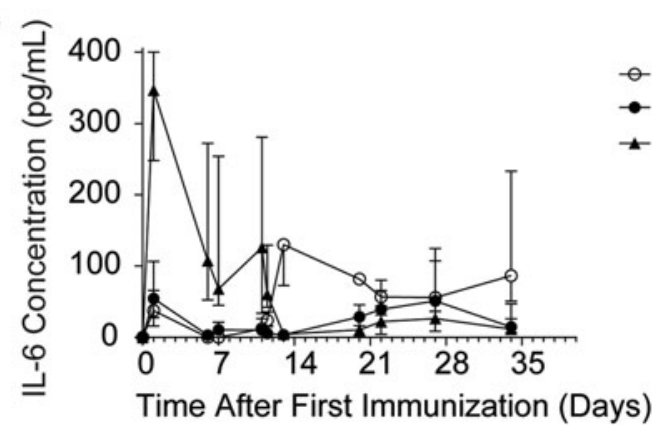

FIG. 5. Effect of SL1026 on plasma IL-6 levels and clinical assessments in collagen-induced arthritis (CIA) monkeys. (A) Animals were sensitized on day 0 and 21 with collagen and dosed with slow off-rate modified aptamer (SOMAmer) every $6 \mathrm{~h}$ on days $0-11$. Plasma was collected and measurements of arthritis score and general condition score were made on days indicated with a dot. Arthritis score (B) and general condition score (C) were evaluated at days 6, 13, 20, 27, and 34 after the first sensitization. Values are plotted as the mean \pm SEM $(n=4$ in each group) for groups administered $0(\bigcirc), 1(\mathbf{O})$, or 10 ( $\Delta$ ) $\mathrm{mg} / \mathrm{kg}$ SL1026. A statistically significant decrease of arthritis score was noted in the $10 \mathrm{mg} / \mathrm{kg}$ group $(* P<0.05$, $10 \mathrm{mg} / \mathrm{kg}$ group vs. $0 \mathrm{mg} / \mathrm{kg}$ group) and of general condition score in both the 1 and $10 \mathrm{mg} / \mathrm{kg}$ groups $(* P<0.05,1$ and $10 \mathrm{mg} / \mathrm{kg}$ groups vs. $0 \mathrm{mg} / \mathrm{kg}$ group) by mixed effect model for repeated measures method in overall mean. (D) IL-6 concentration was measured in plasma samples collected at various times after the first immunization. Values are plotted as the median and interquartile range ( $n=4$ in each group) for groups administered $0(\bigcirc), 1(\boldsymbol{O})$, or $10(\boldsymbol{\Delta}) \mathrm{mg} / \mathrm{kg}$ SL1026.
SL1026 dose-dependent improvements in both arthritis score and general condition score were observed in this study.

\section{Plasma SL1026 concentration in monkeys with CIA}

Plasma SL1026 concentrations were measured throughout the CIA study and are shown in Table 2 . The concentrations of SL1026 $5 \mathrm{~min}$ after the first 1 or $10 \mathrm{mg} / \mathrm{kg}$ dose were 19.4 and $184 \mu \mathrm{g} / \mathrm{mL}(1.6$ and $15.4 \mu \mathrm{M})$, respectively, reflecting the dose-dependent initial exposure on day 0. Peak plasma concentrations measured on days 7 and 11 were similar to those on day 0 . To determine the trough plasma concentrations, plasma samples were collected immediately before the first SL1026 administration of day 1 (5th dose) and day 6 (25th dose). SL1026 trough concentrations in the $10 \mathrm{mg} / \mathrm{kg}$ group were significantly greater than predicted by the singledose concentration-time profile. In both the 1 and $10 \mathrm{mg} / \mathrm{kg}$ groups, the mean plasma trough concentrations on day 6 were $2-3$ times greater than on day $1(0.018 \mu \mathrm{g} / \mathrm{mL}$ and $0.049 \mu \mathrm{g} / \mathrm{mL}$ on day 1 and day 6 , respectively for the $1 \mathrm{mg} / \mathrm{kg}$ group, and $12.7 \mu \mathrm{g} / \mathrm{mL}$ and $26.6 \mu \mathrm{g} / \mathrm{mL}$ on day 1 and day 6 , respectively for the $10 \mathrm{mg} / \mathrm{kg}$ group). Furthermore, SL1026 was still detectable in the plasma at $0.011 \mu \mathrm{g} / \mathrm{mL}(1 \mathrm{mg} / \mathrm{kg}$ group) and $0.082 \mu \mathrm{g} / \mathrm{mL}(10 \mathrm{mg} / \mathrm{kg}$ group) on day $13, \sim 48 \mathrm{~h}$ after the final administration.

\section{Plasma IL-6 concentration in SL1026-treated monkeys}

In control monkeys, median plasma concentrations of IL-6 remained at or below $37.8 \mathrm{pg} / \mathrm{mL}$ throughout the dosing period (days $0-11$ ), but rapidly increased to $130 \mathrm{pg} / \mathrm{mL}$ on day 13 and then remained at or above $56.0 \mathrm{pg} / \mathrm{mL}$ through day 34 (Fig. 5D). In monkeys administered $10 \mathrm{mg} / \mathrm{kg}$ SL1026, median IL-6 concentrations dramatically increased to $347 \mathrm{pg} / \mathrm{mL}$ on day 1 , but then steadily decreased to $4.7 \mathrm{pg} / \mathrm{mL}$ by day 13 where median values remained at or below $26.4 \mathrm{pg} / \mathrm{mL}$ through day 34. In monkeys administered $1 \mathrm{mg} / \mathrm{kg}$ SL1026, median IL-6 concentrations were similar to the control group during the treatment period and showed only a moderate increase from days 13-34, peaking at $51.1 \mathrm{pg} / \mathrm{mL}$ on day 27 . On the final day of the study (day 34), the difference between

Table 2. Mean Peak and Trough Sl1026 Plasma Concentrations After the First Dose Administration OF THE INDICATED STUdy Day IN CyNOMOlgus Monkeys with Collagen-Induced Arthritis

\begin{tabular}{|c|c|c|c|c|c|c|}
\hline & \multicolumn{6}{|c|}{ SL1026 concentration $(\mu \mathrm{g} / \mathrm{mL})$} \\
\hline & Day 0 & Day 1 & Day 6 & Day 7 & Day 11 & Day 13 \\
\hline \multicolumn{7}{|l|}{$1 \mathrm{mg} / \mathrm{kg}$} \\
\hline Peak $^{\mathrm{a}}$ & 19.4 & - & - & 19.7 & 19.1 & - \\
\hline Trough $^{b}$ & - & 0.018 & 0.049 & - & - & - \\
\hline $\begin{array}{l}48 \mathrm{~h} \text { after } \\
\text { last dose }\end{array}$ & - & - & - & - & - & 0.011 \\
\hline \multicolumn{7}{|l|}{$10 \mathrm{mg} / \mathrm{kg}$} \\
\hline Peak $^{a}$ & 184 & - & - & 172 & 164 & - \\
\hline Trough $^{b}$ & - & 12.7 & 26.6 & - & - & - \\
\hline $\begin{array}{l}48 \mathrm{~h} \text { after } \\
\text { last dose }\end{array}$ & - & - & - & 一 & - & 0.082 \\
\hline
\end{tabular}

${ }^{\text {a }}$ Sample collected $5 \mathrm{~min}$ after first dose on indicated day.

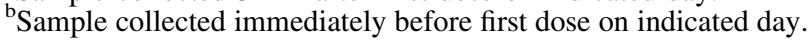
Mean values are reported $(n=4)$. 
median IL-6 concentrations in the SL1026 treatment groups was significantly different than the control group $(P=0.0263)$. After dosing, a trend toward reduced IL-6 concentrations was observed in SL1026-treated animals compared to control animals $(P=0.079$ for $1 \mathrm{mg} / \mathrm{kg}$ SL1026 vs. control and $P=0.037$ for $10 \mathrm{mg} / \mathrm{kg} \mathrm{SL1026} \mathrm{vs.} \mathrm{control).}$

\section{Plasma anti-SL1026 antibody titers in monkeys treated with SL1026}

We screened for production of antibodies against the DNA and PEG components of SL1026. Compared to predose, no anti-SL1026 antibodies were detected for the DNA or PEG components of SL1026 over the 34-day experimental period (Fig. 6). The coating of the DNA and PEG components was confirmed with anti-DNA and anti-PEG antibodies. No signal was observed in this assay with normal monkey plasma (data not shown).

\section{Discussion}

The nonhuman primate CIA model is an established system for studying RA [37], and the therapeutic and preventive effects of several existing drugs, including tocilizumab, have been assessed in this model [38]. Animals display an
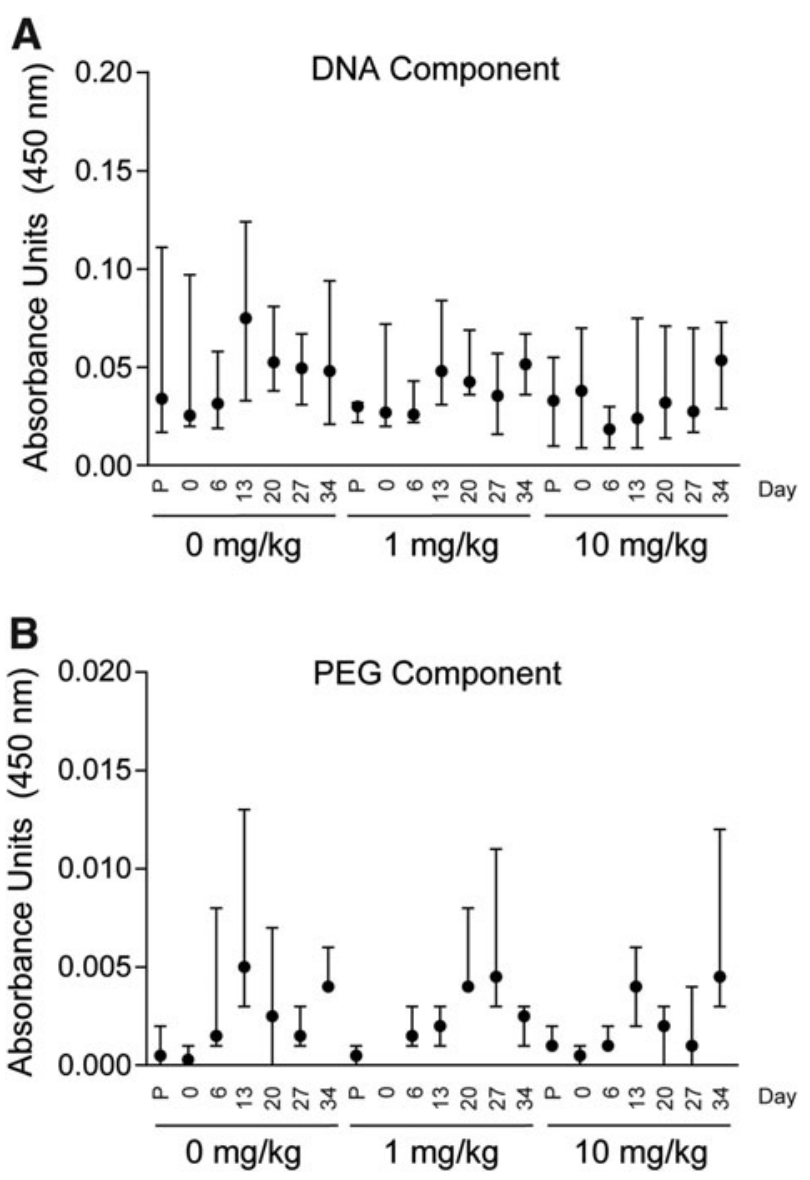

FIG. 6. Anti-SL1026 antibody levels in CIA monkeys. Antibodies against the DNA component of SL1026 (A) and the PEG component of SL1026 (B) were measured in plasma collected from all monkeys 6 days before the first SL1026 dose (P), and on days 0, 6, 13, 20, 27, and 34 after the first SL1026 dose. Values are plotted as median and range ( $n=4$ in each group). autoimmune-mediated polyarthritis, synovitis, and erosion of cartilage and bone [37,39,40]. These symptoms begin to manifest at the clinical onset of arthritis [41], and are similar to human RA [42]. As in human RA, IL-6 is believed to be one of the important triggers in this monkey model, and is thought to play a key role in contributing to the severity of disease [43]. SL1026 treatment delayed the onset of arthritis in monkeys in this study and reduced the severity of symptoms. Not only did joint swelling and stiffness occur at a lower frequency in monkeys treated with SL1026 compared to the control monkeys, but also an overall improvement in general health condition was observed. Furthermore, SOMAmer treatment resulted in a sustained reduction in plasma IL-6 levels that corresponded precisely with the reduction in RA symptoms.

SL1026 administration began on the day animals received their first collagen immunization. Thus, SL1026 was given before the expected increase in serum IL-6, allowing SL1026 to access target tissues before the onset of inflammation. Results from the single-dose pharmacokinetic study in monkeys indicated an expected plasma concentration of $13 \mathrm{ng} / \mathrm{mL}(1 \mathrm{nM})$ at $6 \mathrm{~h}$ after administration of a $10 \mathrm{mg} / \mathrm{kg}$ dose (Fig. 4). Based on these results, a dosing regimen of four administrations per day was chosen to ensure a plasma concentration of SL1026 in excess of the in vitro $\mathrm{IC}_{50}$ value $(2.4 \mathrm{nM})$ [29] for nearly the entire dosing interval for the $10 \mathrm{mg} / \mathrm{kg}$ dose. SL1026 measurements in samples collected during the study (Table 2) indicated that SL1026 concentrations remained above the IL- 6 concentration (less than $500 \mathrm{pg} / \mathrm{mL}$, Fig. 5D) at both dosing concentrations.

The trough concentrations of SL1026 were $0.018 \mu \mathrm{g} / \mathrm{mL}$ and $0.049 \mu \mathrm{g} / \mathrm{mL}$ in plasma collected $5 \mathrm{~min}$ before the 5 th and 25 th dose at $1 \mathrm{mg} / \mathrm{kg}$, and $12.7 \mu \mathrm{g} / \mathrm{mL}$ and $26.6 \mu \mathrm{g} / \mathrm{mL}$ in plasma collected $5 \mathrm{~min}$ before the 5 th and 25 th dose at $10 \mathrm{mg} /$ $\mathrm{kg}, \sim 1,000$-fold greater than predicted by the single-dose concentration-time profile. This suggests that the clearance rate was decreasing after repeated doses, perhaps due to saturation of a clearance mechanism, allowing measurable concentrations of SL1026 (11 and $82 \mathrm{ng} / \mathrm{mL}$ in the low- and high-dose groups, respectively) to remain in the plasma on day 13, 48 h after the final administration. Even if SL1026 concentrations dropped below the presumed pharmacologically effective level in plasma after the last administration, we expected SL1026 to accumulate in target tissues, such as articular cavities, by the enhanced permeation and retention effect [44-46]. Thus, pharmacologically effective concentrations of SL1026 might have persisted at the target tissues long after the final dose and contributed to the overall inhibition of the onset of arthritis in joints and restoration of the general health condition of the treated animals.

Serum IL-6 levels reflect the normal endogenous production of IL-6 [47], and IL-6 is an important serum biomarker for treatments that exert their effects through IL-6 signal inhibition. The rate of IL-6 clearance from the blood is increased significantly upon binding IL-6R [48], and anti-IL6R antibodies such as tocilizumab block this clearance mechanism, leading to a temporary increase in free IL-6 levels in serum of animals and humans $[47,48]$. While tocilizumab significantly reduces the disease activity of RA by effectively inhibiting IL-6 signal transduction and the subsequent anti-inflammatory response $[49,50]$, the increase in blood levels of free IL-6 may result in high IL-6 exposure to organs during drug treatment. 
Horai et al. reported serum IL-6 concentrations in monkeys when CIA begin to rise at about 14 days after the first immunization and peak at 21-28 days [37]. This observation was recapitulated in our control group, but in the treatment groups, an increase in total serum IL-6 was observed during the drug administration period, particularly at the high dose (Fig. 5D). IL-6 concentrations returned to baseline in the treatment groups after administration of the final dose on day 11 , and were consistently lower than in the control group from days 13-34 during the expected peak period. Notably, arthritis scores and general health scores in the treatment groups were lower than those in the control group during this same period. IL-6 levels in the $1 \mathrm{mg} / \mathrm{kg}$ dose group were only slightly greater than the control group during SL1026 dosing, but remained lower than the control group after dosing, providing an intermediate reduction in RA symptoms.

Because SL1026 is known to block binding of IL-6 to IL6R, the IL-6 spike during SOMAmer administration may have been due to interference of receptor-dependent IL-6 elimination, as was observed with tocilizumab. Additionally, the rise in IL-6 levels during SOMAmer administration may be an indication of an on-target effect commonly seen with antibody drugs, where inhibitor binding alters the rates of target distribution and elimination, resulting in increased plasma target concentrations. [51-53]. However, while total IL-6 levels increased during SL1026 administration, free IL-6 levels likely decreased, as the majority of serum IL-6 existed as a complex with SOMAmer and was, therefore, inactive (IL6 was not detected in plasma after depletion of SL1026:IL-6 complexes with anti-PEG antibody-coated beads, data not shown). This inhibition of IL-6 activity during the early stages of disease development led to the reduction in RA symptoms in both dose groups. We worried that the rise in IL-6 levels during SOMAmer dosing could be due to activation of toll-like receptors (TLR) by SL1026, or contaminating endotoxin. However, no evidence of TLR9 activation was observed in an in vitro cellular assay with as much as $230 \mu \mathrm{M}$ SL1026 (data not shown), and the endotoxin level in the test material was below the detectable measurement limit $(<0.009 \mathrm{EU} / \mathrm{mg})$.

Activation of $\mathrm{CD}^{+}{ }^{+}$lymphocytes has been observed in the earliest clinical stage of RA [54], and IL-6 induction of STAT3 phosphorylation in T lymphocytes is believed to be closely associated with RA [55-57]. SL1026 fully inhibited IL6 signaling and STAT3 phosphorylation in isolated human T lymphocytes with potency comparable to tocilizumab. Additionally, IL-6 induces production of CRP and SAA by hepatocytes, and tocilizumab was previously shown to inhibit this activity by blocking the IL-6 signal transduction pathway [19]. Similar to tocilizumab, SL1026 exhibited dose-dependent inhibition of IL-6-induced production of CRP and SAA by isolated human primary hepatocytes. These ex vivo results further support the in vivo observations and indicate that the suppression of RA symptoms in the CIA model resulted directly or indirectly from IL-6 signal inhibition by SL1026.

Due to the clinical success of tocilizumab, IL-6 signal blockade is considered to be a powerful therapeutic strategy for the treatment of RA. Many other biologics targeting IL-6 are in development [58,59], including other anti-IL-6R antibodies (such as sarilumab [60]), anti-IL-6 antibodies (such as sirukumab [61], siltuximab [62], clazakizumab [63], and olokizumab), and anti-gp130 antibodies and their fusion proteins [64]. All of these agents are antibodies or synthe- sized proteins, while SL1026 is a nucleic acid-based antagonist with certain advantages over antibody drugs in vivo. Antibody drugs can induce an immune response in patients after several administrations, whereby neutralizing antibodies are generated against the drug and generally weaken its efficacy $[38,65,66]$. This has not been observed for aptamer therapies to date, and in this study, anti-SL1026 antibodies were not detectable in any of the monkeys during the examination period. Furthermore, the aggressive dosing regimen of up to $10 \mathrm{mg} / \mathrm{kg}$ of SL1026 every $6 \mathrm{~h}$ for 11 days was well tolerated in all animals and no adverse effects were observed.

IL-6 is a multifunctional cytokine that promotes cell growth and differentiation and influences the expression of a variety of proteins. In addition to its role in inflammation, IL-6 is known to regulate tumor development, including initiation, promotion, malignant conversion, invasion, and metastasis, and a relationship between IL-6 expression and cancer pathology has been reported [67]. SL1026 was previously shown to inhibit the growth of several tumor cell lines in vitro [29], and has the potential to be an effective suppressor of tumor proliferation in vivo. These combined studies confirm that SL1026 is a potent antagonist of the IL-6 signaling pathway and represents a new class of drug candidate for the treatment of IL-6-mediated diseases including RA, inflammation, and cancer.

\section{Acknowledgments}

The authors thank Shiro Tochizawa for thoughtful suggestions for ex vivo studies, Yoshihiro Taniguchi and Tomonori Tahara for fruitful discussions about the CIA model, Keiji Kakumoto for effective advice on statistical analyses, and Amy Gelinas for Fig. 1 illustrations.

\section{Author Disclosure Statement}

No competing financial interests exist.

\section{References}

1. Harris ED. (1990). Rheumatoid arthritis. Pathophysiology and implications for therapy. New Engl J Med 322:12771289.

2. McInnes IB and G Schett. (2007). Cytokines in the pathogenesis of rheumatoid arthritis. Nat Rev Immunol 7: 429-442.

3. Choy EH and GS Panayi. (2001). Cytokine pathways and joint inflammation in rheumatoid arthritis. New Engl J Med 344:907-916.

4. Takeuchi T and H Kameda. (2010). The Japanese experience with biologic therapies for rheumatoid arthritis. Nat Rev Rheumatol 6:644-652.

5. Rendas-Baum R, GV Wallenstein, T Koncz, M Kosinski, M Yang, et al. (2011). Evaluating the efficacy of sequential biologic therapies for rheumatoid arthritis patients with an inadequate response to tumor necrosis factor-alpha inhibitors. Arthritis Res Ther 13:R25.

6. Yoshida Y and Tanaka T. (2014). Interleukin 6 and rheumatoid arthritis. Biomed Res Int 2014:e698313.

7. Hirano T, T Matsuda, M Turner, N Miyasaka, G Buchan, et al. (1988). Excessive production of interleukin 6/B cell stimulatory factor-2 in rheumatoid arthritis. Eur J Immunol 18:1797-1801. 
8. Houssiau FA, JP Devogelaer, J Van Damme, CN de Deuxchaisnes and J Van Snick. (1988). Interleukin-6 in synovial fluid and serum of patients with rheumatoid arthritis and other inflammatory arthritides. Arthritis Rheum 31:784-788.

9. Guerne PA, BL Zuraw, JH Vaughan, DA Carson and M Lotz. (1989). Synovium as a source of interleukin 6 in vitro. Contribution to local and systemic manifestations of arthritis. J Clin Invest 83:585-592.

10. Berthelot JM, R Bataille, Y Maugars and A Prost. (1996). Rheumatoid arthritis as a bone marrow disorder. Semin Arthritis Rheum 26:505-514.

11. Yusof MY and P Emery. (2013). Targeting interleukin-6 in rheumatoid arthritis. Drugs 73:341-356.

12. Madhok R, A Crilly, J Watson and HA Capell. (1993). Serum interleukin 6 levels in rheumatoid arthritis: correlations with clinical and laboratory indices of disease activity. Ann Rheum Dis 52:232-234.

13. Kotake S, K Sato, KJ Kim, N Takahashi, N Udagawa, et al. (1996). Interleukin-6 and soluble interleukin-6 receptors in the synovial fluids from rheumatoid arthritis patients are responsible for osteoclast-like cell formation. J Bone Miner Res 11:88-95.

14. Yoshizaki K, N Nishimoto, M Mihara and T Kishimoto. (1998). Therapy of rheumatoid arthritis by blocking IL-6 signal transduction with a humanized anti-IL-6 receptor antibody. Springer Semin Immun 20:247-259.

15. Kang S, T Tanaka and T Kishimoto. (2015). Therapeutic uses of anti-interleukin-6 receptor antibody. Int Immunol 27:21-29.

16. Yokota S, T Imagawa, M Mori, T Miyamae, Y Aihara, et al. (2008). Efficacy and safety of tocilizumab in patients with systemic-onset juvenile idiopathic arthritis: a randomised, double-blind, placebo-controlled, withdrawal phase III trial. Lancet 371:998-1006.

17. Kishimoto T. (1989). The biology of interleukin-6. Blood $74: 1-10$.

18. Ishihara $\mathrm{K}$ and $\mathrm{T}$ Hirano. (2002). IL-6 in autoimmune disease and chronic inflammatory proliferative disease. Cytokine Growth Factor Rev 13:357-368.

19. Nishimoto $\mathrm{N}$ and T Kishimoto. (2004). Inhibition of IL-6 for the treatment of inflammatory diseases. Curr Opin Pharmacol 4:386-391.

20. Kishimoto T. (2010). IL-6: from its discovery to clinical applications. Int Immunol 22:347-352.

21. Kishimoto T, S Akira, M Narazaki and T Taga. (1995). Interleukin-6 family of cytokines and gp130. Blood 86: 1243-1254.

22. Heinrich PC, I Behrmann, G Muller-Newen, F Schaper and L Graeve. (1998). Interleukin-6-type cytokine signalling through the gp130/Jak/STAT pathway. Biochem J 334:297-314.

23. Minami M, M Inoue, S Wei, K Takeda, M Matsumoto, et al. (1996). STAT3 activation is a critical step in gp130mediated terminal differentiation and growth arrest of a myeloid cell line. Proc Natl Acad Sci U S A 93:3963-3966.

24. Nakajima K, Y Yamanaka, K Nakae, H Kojima, M Ichiba, et al. (1996). A central role for Stat3 in IL-6-induced regulation of growth and differentiation in M1 leukemia cells. EMBO J 15:3651-3658.

25. Hirano T, K Ishihara and M Hibi. (2000). Roles of STAT3 in mediating the cell growth, differentiation and survival signals relayed through the IL-6 family of cytokine receptors. Oncogene 19:2548-2556.

26. Honda M, S Yamamoto, M Cheng, K Yasukawa, H Suzuki, et al. (1992). Human soluble IL-6 receptor: its detection and enhanced release by HIV infection. J Immunol 148:2175-2180.
27. Novick D, H Engelmann, D Wallach and M Rubinstein. (1989). Soluble cytokine receptors are present in normal human urine. J Exp Med 170:1409-1414.

28. Rose-John S. (2012). IL-6 trans-signaling via the soluble IL-6 receptor: importance for the pro-inflammatory activities of IL-6. Int J Biol Sci 8:1237-1247.

29. Gupta S, M Hirota, SM Waugh, I Murakami, T Suzuki, et al. (2014). Chemically modified DNA aptamers bind interleukin-6 with high affinity and inhibit signaling by blocking its interaction with interleukin-6 receptor. J Biol Chem 289:8706-8719.

30. Vaught JD, C Bock, J Carter, T Fitzwater, M Otis, et al. (2010). Expanding the chemistry of DNA for in vitro selection. J Am Chem Soc 132:4141-4151.

31. Gelinas AD, DR Davies, TE Edwards, JC Rohloff, JD Carter, et al. (2014). Crystal structure of interleukin-6 in complex with a modified nucleic acid ligand. J Biol Chem 289:8720-8734.

32. Davies DR, AD Gelinas, C Zhang, JC Rohloff, JD Carter, et al. (2012). Unique motifs and hydrophobic interactions shape the binding of modified DNA ligands to protein targets. Proc Natl Acad Sci U S A 109:19971-19976.

33. Gold L, D Ayers, J Bertino, C Bock, A Bock, et al. (2010). Aptamer-based multiplexed proteomic technology for biomarker discovery. PLoS One 5:e15004.

34. Wachtel R and K Tsuji. (1977). Comparison of limulus amebocyte lysates and correlation with the United States Pharmacopeial pyrogen test. Appl Environ Microbiol 33: 1265-1269.

35. Tochizawa S, Y Ohmoto and T Mori. (2006). A novel modification of a flow cytometric assay of phosphorylated STAT1 in whole blood lymphocytes for rapid detection of interferonalpha signal in vivo. J Immunol Methods 313:29-37.

36. Drolet DW, J Nelson, CE Tucker, PM Zack, K Nixon, et al. (2000). Pharmacokinetics and safety of an anti-vascular endothelial growth factor aptamer (NX1838) following injection into the vitreous humor of rhesus monkeys. Pharm Res 17:1503-1510.

37. Horai N, T Nagaoka, I Higuchi, H Kasai, T Yoshioka, et al. (2013). Muscle wasting associated with pathologic change is a risk factor for the exacerbation of joint swelling in collagen-induced arthritis in cynomolgus monkeys. BMC Musculoskel Dis 14:205-214.

38. Uchiyama $\mathrm{Y}, \mathrm{K}$ Yorozu, $\mathrm{M}$ Hashizume, $\mathrm{Y}$ Moriya and $\mathrm{M}$ Mihara. (2008). Tocilizumab, a humanized anti-interleukin6 receptor antibody, ameliorates joint swelling in established monkey collagen-induced arthritis. Biol Pharm Bull 31:1159-1163.

39. Offner H, GS Firestein, DL Boyle, R Pieters, JM Frincke, et al. (2009). An orally bioavailable synthetic analog of an active dehydroepiandrosterone metabolite reduces established disease in rodent models of rheumatoid arthritis. J Pharmacol Exp Ther 329:1100-1109.

40. Fujii Y, T Hirayama, H Ohtake, N Ono, $\mathrm{T}$ Inoue, et al. (2012). Amelioration of collagen-induced arthritis by a novel S1P1 antagonist with immunomodulatory activities. J Immunol 188:206-215.

41. Ushio H, S Ishibuchi, K Oshita, N Seki, H Kataoka, et al. (2013). A new phenylpyrazoleanilide, y-320, inhibits interleukin 17 production and ameliorates collagen-induced arthritis in mice and cynomolgus monkeys. Pharmaceuticals 7:1-17.

42. Trentham DE, AS Townes and AH Kang. (1977). Autoimmunity to type II collagen an experimental model of arthritis. J Exp Med 146:857-868. 
43. Alonzi T, E Fattori, D Lazzaro, P Costa, L Probert, et al. (1998). Interleukin 6 is required for the development of collagen-induced arthritis. J Exp Med 187:461-468.

44. Milla P, F Dosio and L Cattel. (2012). PEGylation of proteins and liposomes: a powerful and flexible strategy to improve the drug delivery. Curr Drug Metab 13:105-119.

45. Gabriel D, N Lange, V Chobaz-Peclat, MF Zuluaga, R Gurny, et al. (2012). Thrombin-sensitive dual fluorescence imaging and therapeutic agent for detection and treatment of synovial inflammation in murine rheumatoid arthritis. J Control Release 163:178-186.

46. Sandanaraj BS, H-U Gremlich, R Kneuer, J Dawson and S Swacha. (2010). Fluorescent nanoprobes as a biomarker for increased vascular permeability: implications in diagnosis and treatment of cancer and inflammation. Bioconjugate Chem 21:93-101.

47. Nishimoto N, K Terao, T Mima, H Nakahara, N Takagi, et al. (2008). Mechanisms and pathologic significances in increase in serum interleukin-6 (IL-6) and soluble IL-6 receptor after administration of an anti-IL-6 receptor antibody, tocilizumab, in patients with rheumatoid arthritis and castleman disease. Blood 112:3959-3964.

48. Uchiyama Y, H Yoshida, N Koike, N Hayakawa, A Sugita, et al. (2008). Anti-IL-6 receptor antibody increases blood IL-6 level via the blockade of IL-6 clearance, but not via the induction of IL-6 production. Int Immunopharmacol 8:1595-1601.

49. Nishimoto N, K Yoshizaki, N Miyasaka, K Yamamoto, S Kawai, et al. (2004). Treatment of rheumatoid arthritis with humanized anti-interleukin- 6 receptor antibody: a multicenter, double-blind, placebo-controlled trial. Arthritis Rheum 50:1761-1769.

50. Nishimoto $\mathrm{N}$ and $\mathrm{N}$ Takagi. (2010). Assessment of the validity of the 28-joint disease activity score using erythrocyte sedimentation rate (DAS28-ESR) as a disease activity index of rheumatoid arthritis in the efficacy evaluation of 24-week treatment with tocilizumab: subanalysis of the SATORI study. Mod Rheumatol 20:539-547.

51. Davda JP and RJ Hansen. (2010). Properties of a general PK/PD model of antibody-ligand interactions for therapeutic antibodies that bind to soluble endogenous targets. mAbs 2:576-588.

52. Hayashi N, Y Tsukamoto, WM Sallas and PJ Lowe. (2007). A mechanism-based binding model for the population pharmacokinetics and pharmacodynamics of omalizumab. Br J Clin Pharmacol 63:548-561.

53. Loyet KM, J Good, T Davancaze, L Sturgeon, X Wang, et al. (2014). Complement inhibition in cynomolgus monkeys by anti-factor D antigen-binding fragment for the treatment of an advanced form of dry age-related macular degeneration. J Pharmacol Exp Ther 351:527-537.

54. Pratt AG, DC Swan, S Richardson, G Wilson, CM Hilkens, et al. (2012). A CD4 T cell gene signature for early rheumatoid arthritis implicates interleukin 6-mediated STAT3 signalling, particularly in anti-citrullinated peptide antibody-negative disease. Ann Rheum Dis 71: 1374-1381.

55. Komatsu N, K Okamoto, S Sawa, T Nakashima, M Ohhora, et al. (2014). Pathogenic conversion of Foxp3+ T cells into TH17 cells in autoimmune arthritis. Nat Med 20:62-68.

56. Moore K, MT Walters, DB Jones, E Garvey, J Harvey, et al. (1988). An immunohistological study of CD4+ lymphocyte subsets within inflammatory lesions with special reference to rheumatoid arthritis and inflammatory bowel disease. Immunology 65:457-463.

57. Steiner G, M Tohidast-Akrad, G Witzmann, M Vesely, A Studnicka-Benke, et al. (1999). Cytokine production by synovial T cells in rheumatoid arthritis. Rheumatology 38: 202-213.

58. Kruspe S, C Meyer and U Hahn. (2014). Chlorin e6 conjugated interleukin-6 receptor aptamers selectively kill target cells upon irradiation. Mol Ther Nucl Acid 3:e143.

59. Igawa T, S Ishii, T Tachibana, A Maeda, Y Higuchi, et al. (2010). Antibody recycling by engineered pH-dependent antigen binding improves the duration of antigen neutralization. Nat Biotechnol 28:1203-1207.

60. Huizinga TWJ, RM Fleischmann, M Jasson, AR Radin, J van Adelsberg, et al. (2014). Sarilumab, a fully human monoclonal antibody against IL-6R $\alpha$ in patients with rheumatoid arthritis and an inadequate response to methotrexate: efficacy and safety results from the randomised SARIL-RAMOBILITY Part A trial. Ann Rheum Dis 73:1626-1634.

61. Xu Z, E Bouman-Thio, C Comisar, B Frederick, B Van Hartingsveldt, et al. (2011). Pharmacokinetics, pharmacodynamics and safety of a human anti-IL-6 monoclonal antibody (sirukumab) in healthy subjects in a first-in-human study. Br J Clin Pharmacol 72:270-281.

62. Rossi JF, S Negrier, ND James, I Kocak, R Hawkins, et al. (2010). A phase I/II study of siltuximab (CNTO 328), an anti-interleukin-6 monoclonal antibody, in metastatic renal cell cancer. Br J Cancer 103:1154-1162.

63. Mease P, V Strand, L Shalamberidze, A Dimic, T Raskina, et al. (2012). A phase II, double-blind, randomised, placebocontrolled study of BMS945429 (ALD518) in patients with rheumatoid arthritis with an inadequate response to methotrexate. Ann Rheum Dis 71:1183-1189.

64. Woodrick RS and EM Ruderman. (2012). IL-6 inhibition for the treatment of rheumatoid arthritis and other conditions. Bull NYU Hosp Jt Dis 70:195-199.

65. Mok CC, D van der Kleij and GJ Wolbink. (2013). Drug levels, anti-drug antibodies, and clinical efficacy of the anti-TNF $\alpha$ biologics in rheumatic diseases. Clin Rheumatol 32:1429-1435.

66. Actemra (tocilizumab) injection label. www.accessdata.fda .gov/drugsatfda_docs/label/2013/125276s092lbl.pdf. 10/22/ 2013.

67. Hodge DR, EM Hurt and WL Farrar. (2005). The role of IL-6 and STAT3 in inflammation and cancer. Eur J Cancer 41:2502-2512.

Address correspondence to: Masao Hirota, PhD Otsuka Pharmaceutical Co., Ltd. 463-10 Kagasuno, Kawauchi-cho Tokushima 771-0192 Japan

E-mail: hirota.masao@otsuka.jp

Daniel J. Schneider, PhD SomaLogic, Inc. 2945 Wilderness Place Boulder, CO 80301

E-mail: dschneider@somalogic.com

Received for publication July 29, 2015; accepted after revision October 6, 2015. 